Int. J. Morphol.,

35(4):1451-1458, 2017.

\title{
A Morphometric Study of Auricular Concha in the Population of Young Chinese Adults
}

\author{
Estudio Morfométrico de la Concha Auricular en una Población de Jóvenes Adultos Chinos
}

\author{
Zhaohua Zhu' ${ }^{1}$ Xiaomin Ji'; Zhu Gao ${ }^{2}$ \& Gang $\mathrm{Hu}^{3}$
}

ZHU, Z.; JI, X.; GAO, Z. \& HU, G. A morphometric study of auricular concha in the population of young Chinese adults. Int. J. Morphol., 35(4):1451-1458, 2017.

SUMMARY: A detailed data of concha is currently not available. Therefore, the present study aimed to determine twelve morphometric measurements of concha, to investigate its sexual dimorphism and bilateral asymmetry, and to establish basic shapes of concha for both sexes and sides. The study sample comprised of 310 young Chinese aged 18-28 years. 141 left and 141 right ear impressions for females, 169 left and 169 right ear impressions for males were collected and scanned. The 3D coordinates of seven landmarks on each auricular concha were obtained using 3D scanning technology and curvature theory. From the landmarks, twelve morphometric measurements of concha were calculated and analyzed. The conchal morphometry exist significantly sexual dimorphism in this study sample. On average, all measurements were larger in males than in females regardless of the sides. There was significantly bilateral asymmetry among left and right conchae in both sexes. Some measurements were larger in the right sides and some measurements were larger in the left sides, but the bilateral difference in both measurements found to be less than $1 \mathrm{~mm}$. Additionally, the basic shapes of concha for both sexes and sides were established on the basis of the mean 3D coordinates of each landmark and the mean value of each measurement. The anthropometric method of this study could overcome the difficulty in locating landmarks of auricle complex structures, and attain a higher level of accuracy in the procedure of measurement. The quantitative description of conchal morphometry will be beneficial for plastic surgeons, and for the ergonomic design of hearing aids.

KEY WORDS: Ear Impression; Anthropometry; Conchal Morphometry; Sexual Dimorphism; Bilateral Asymmetry.

\section{INTRODUCTION}

The human auricle is composed of the helixantihelical complex, the conchal complex and the lobule, which is the most distinctive feature of the human face, and is particularly influential in determining its appearance (Alexander et al., 2011; Ahmed \& Omer, 2015). It is wellestablished fact that a detailed knowledge of the morphologic dimensions, location and asymmetry of normal auricle is essential for the diagnosis of congenital abnormalities and syndromes, forensic investigations and for the ergonomic design of hearing aids (Coward et al., 2000; Purkait \& Singh, 2007; Tatlisumak et al., 2015). Therefore, a large number of anthropometric studies of normal auricle have been assessed in various populations, for instance, Koreans (Jung \& Jung, 2003; Kang et al., 2006), Sudanese Arabs (Ahmed \& Omer), Chinese (Liu, 2008; Wang et al., 2011) Indians (Purkait \& Singh; Sharma et al., 2007; Purkait, 2013), Italians (GualdiRusso, 1998; Ferrario et al., 1999; Sforza et al., 2009), Britons (Coward et al.; Alexander et al.), Turks (Bozkir et al., 2006; Barut \& Aktunc, 2006), Americans (Brucker et al., 2003), Germans (Niemitz et al., 2007), and Japanese (Asai et al., 1996). The shape, dimension and orientation of each auricle is as individual as a fingerprint (Murgod et al., 2013), but it is possible to make some generalisations from the studies mentioned above. (1) The mean dimensions of auricle are larger in males than in females regardless of ethnicity. (2) The dimensions of auricle increase with increasing age. (3) Significant differences in ear dimensions exist among various ethnicities (e.g., Europeans have larger ear dimensions than Asians), suggesting that it is not suitable to use foreign standards of auricle dimensions as a guideline for Chinese.

The previous studies mainly inclined to assess ear length and width, lobule length and width, conchal length and width, and the types of lobule (attached, intermediate, and free types). However, none of the previous studies have

\footnotetext{
${ }^{1}$ School of Mechanical and Precision Instrument Engineering, Xi' an University of Technology, No. 5 Jinhua Road, Xi' an 710048, China.

${ }^{2}$ School of Art and Design, Shanghai University of Engineering Science, No.333 Longteng Road, Songjiang District, Shanghai 201620, China.

${ }^{3}$ School of Science, Xi' an University of Technology, No.5 Jinhua Road, Xi' an 710048, China.

This study is supported by the National Natural Science Foundation of China (No.51305344).
} 
determined one quite comprehensive introduction to the dimensions and morphology of auricular concha, notwithstanding it is an essential segment of auricle.

Several different methods are used for the anthropometric measurement of auricle. In generally, these can be divide into contactable (Vernier calipers and ruler, etc.) and non-contactable methods (3D scanner, computed tomography, magnetic resonance imaging and photography) (Liu et al., 2010). No matter what kinds of methods are used, the location of soft-tissue landmarks of the auricle is the foundation for anthropometry (Wang et al.). The previous studies identified the soft-tissue landmarks of auricle primarily helped by ordinary operators, which may prone to inaccuracy because of the uneven experience and the distortion of the soft-tissue landmarks of the auricle.

This study has two innovations. Firstly, the study sought to provide an anthropometric method to extract the anatomical landmarks of concha automatically and accurately. This method combined 3D scanning technology with curvature theory to capture the 3D coordinates of landmarks on each auricular concha, which could overcome the difficulty in locating landmarks and avoid the artificial error in the procedure of anthropometric measurement. Secondly, the current study aimed to determine twelve morphometric measurements of auricular concha for young Chinese adults, to investigate sexual dimorphism and bilateral asymmetry, and to establish basic shapes of auricular concha for both sexes and sides.

\section{MATERIAL AND METHOD}

Sample. The study sample composed of 310 healthy young Chinese volunteers (141 females and 169 males) aged 1828 years. The mean age for females was $21.34 \pm 2.62$ years and that for males was $20.27 \pm 2.01$ years. All participants were students in universities located in different provinces of China. All volunteers with a previous history of craniofacial trauma, congenital anomalies, ear surgery were excluded in the sample. 141 left and 141 right ear impressions for females, 169 left and 169 right ear impressions for males were collected and scanned from the participants (Fig. 1) by use of the Einscan-S scanner with an accuracy of $0.1 \mathrm{~mm}$ and shinning 3D scan software V1.7.1. This study has been approved by the Institutional Ethics Committee.

Extract the 3D coordinates of conchal landmarks. Figure 2a shows the conchal segment of the ear impression. It can be observed that the conchal shapes are primarily effected by seven anatomical landmarks (Figs. $2 \mathrm{~b}$ and 2c), which are

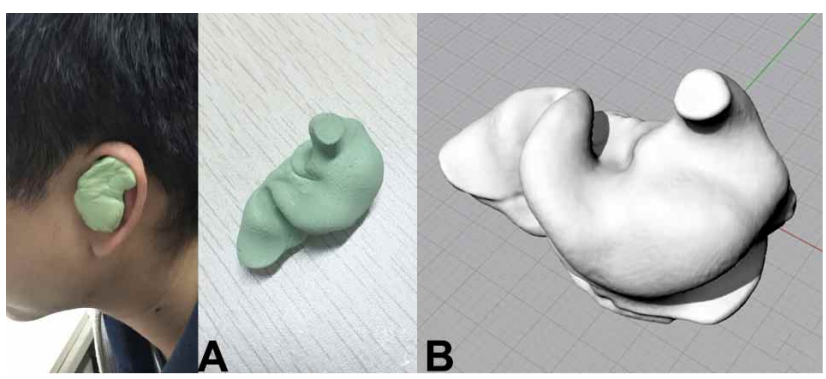

Fig. 1. Collect and scan ear impressions. (a) Collect ear impressions; (b) Scan them into 3D digital models.

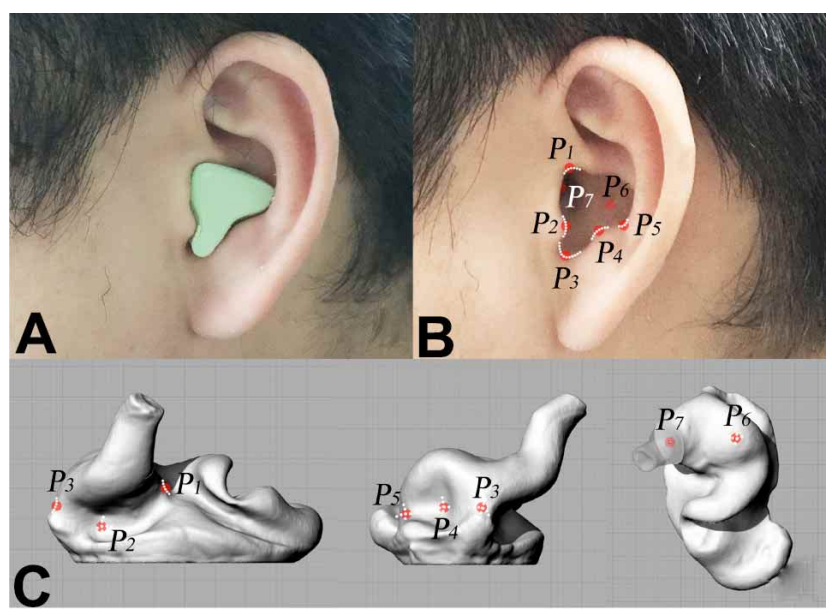

Fig. 2. The anatomical landmarks of auricular concha. (a) The conchal segment of ear impression; (b) and (c) The anatomical landmarks P1, P2, P3, P4, P5, P6, and P7.

(P1) the most posterior point on the edge of the incisura anterior auris; (P2) the bump point of tragus; (P3) the deepest point in the incisura intertragica notch; $(\mathrm{P} 4)$ the bump point of antitragus; (P5) the strongest antihelical curvature; (P6) the deepest point on the floor of auricular concha; (P7) the central point of the ear canal opening.

Each landmarks of the auricular concha except the central point of ear canal opening (P7) occurs in a local small region of the surface with minimum curvature radius (Figs. $2 \mathrm{~b}$ and $2 \mathrm{c}$ ). On the basis of this observation, a RhinoScript code was written to find the maximum curvature point in a local area of 3D digital model. The steps to extract the 3D coordinates of landmarks are follows (Fig. 3 is an example shows the steps to extract 3D coordinates of landmarks P4). (1) Extract the point cloud of a small region around landmarks $\mathrm{P} 4$ by use of the plug-in of Rhino-Resurf running in Rhinoceros 4.0 (Robert McNeel \& Assoc Inc., USA) (Fig. 3a). (2) Transform the point cloud into an NURBS surface and mesh the surface in Rhinoceros 4.0 (Fig. 3b). (3) Extract all 3D coordinates $(\mathrm{x}, \mathrm{y}, \mathrm{z})$ of the mesh nodes and their two curvature radius $\mathrm{R} 1$ and $\mathrm{R} 2$ ( $\mathrm{U}$ and $\mathrm{V}$ direction, respectively) automatically using the written RhinoScript code in 


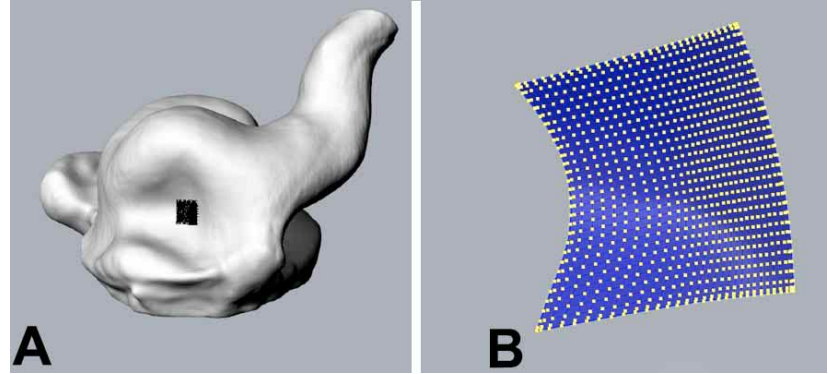

Fig. 3. Extract the 3D coordinates of landmark P4. (a) Extract the point cloud around the landmark P4 from 3D digital model; (b) Convert point cloud into NURBS surface and mesh the surface.

Rhinoceros 4.0. Then, write all the data into a text file. (4) On the basis of the text file, calculate the mean curvature radius $\mathrm{R}=(\mathrm{R} 1+\mathrm{R} 2) / 2$ and Gauss curvature radius $\mathrm{R}^{\prime}=\mathrm{R} 1$ $\mathrm{x}$ R2 in a written Visual Basic code. The point with minimum values of $\mathrm{R}$ and $\mathrm{R}$ ' is considered the landmark P4. Then, record the coordinates $(\mathrm{x}, \mathrm{y}, \mathrm{z})$ of landmark $\mathrm{P} 4$ in a data file. (5) Repeat steps (1) to (4) to obtain the 3D coordinates of other landmarks.

This study utilized another method to extract the 3D coordinates of landmark P7 (the central point of the ear canal opening). The location of the ear canal opening has been determined by previous studies (Alvord \& Farmer, 1997; Yu et al., 2015). According to these studies, it can be observed that the landmarks G1, G2, and G3 are on the edge of the ear canal opening, which also with the minimum curvature radius in a local small region of 3D digital model (Figs. 4a and $4 \mathrm{~b}$ ). Then, the 3D coordinates of landmarks G1, G2, and G3 were extracted using the method mentioned above. The ear canal opening would be the intersected region
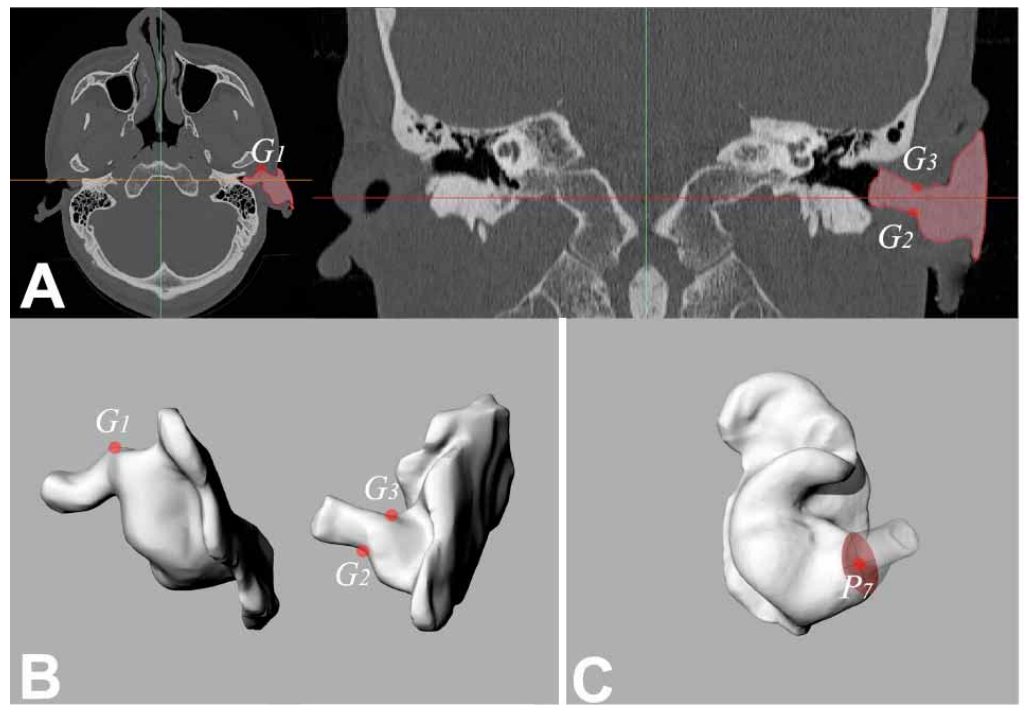

Fig. 4. Calculate the central point of the ear canal opening (P7). (a) and (b) Determine the location of the ear canal opening; (c) Calculate the 3D coordinates of the central point of the ear canal opening (P7). between the enlarged plane G1G2G3 and the 3D digital model of ear impression (Fig. 4c). Furthermore, the $x, y, z$ coordinates of landmark P7 was calculated (Fig. 4c).

Data analysis. The $\mathrm{x}, \mathrm{y}, \mathrm{z}$ coordinates of the seven landmarks obtained on each subject were used to calculate the following measurements (Fig. 5):

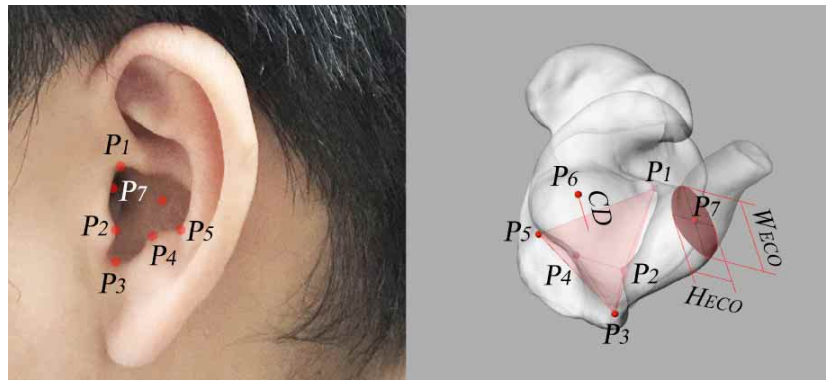

Fig. 5. Twelve measurements of auricular concha.

TL (P1 to P3), the total length of tragus, the linear distance from the most posterior point on the edge of the incisura anterior auris to the deepest point in the incisura intertragic notch.

TL1 (P1 to P2), tragus length 1, the linear distance from the most posterior point on the edge of the incisura anterior auris to the bump point of tragus.

TL2 (P2 to P3), tragus length 2, the linear distance from the bump point of tragus to the deepest point in the incisura intertragic notch.

ATL (P3 to P5), the total length of antitragus, the linear distance from the deepest point in the incisura intertragic notch to the strongest antihelical curvature.

ATL1 (P3 to P4), the antitragus length 1, the linear distance from the deepest point in the incisura intertragic notch and the bump point of antitragus.

ATL2 (P4 to P5), the antitragus length 2, the linear distance from the bump point of antitragus to the strongest antihelical curvature. CW (P1 to P5), the conchal width, the linear distance from the most posterior point on the edge of the incisura anterior auris to the strongest antihelical curvature.

$\mathrm{BD}$ ( $\mathrm{P} 2$ to $\mathrm{P} 4)$, the linear distance from the bump point of tragus to the bump point of antitragus.

HECO, The height of the ear canal opening. WECO, The width of the ear canal opening. CD (P6 to plane P1P3P5), the conchal depth, the vertical distance from the deepest point of auricular concha to the plane P1P3P5.

$\angle \theta$, The angel between the plane P1P3P5 and the ear canal opening. 
The data were analyzed using the SPSS 22.0 software package for Window (SPSS Inc., USA). The descriptive statistics for all measurements (means, standard deviations, maximum and minimum) in both sexes and sides were computed. An independent t-test was used to assess the presence of statistically significant sexual dimorphism between males and females in conchal measurements. Moreover, the paired t-test was used to evaluate the differences between the left and right sides for both sexes. $\mathrm{P}$-values $<0.05$ were considered to be statistically significant.

\section{RESULTS}

The mean, standard deviation, maximum and minimum of the twelve conchal measurements for both sexes and sides are presented in Table I. The results revealed that the mean values of all measurements were all larger in males than the corresponding ones in females regardless of the side $(\mathrm{p}<0.05)$, but the significance value for $\angle \theta$ did not reach the level of statistical significance $(\mathrm{P}>0.05)$. This result demonstrated the presence of sexual dimorphism in present study sample. The greatest dimorphism were left auricular concha width $(\mathrm{CW})$ followed by the right tragus length 1 (TL1). The least sexual dimorphism was the right antitragus length 2 (ATL2).

Left-right differences in the conchal measurements for both sexes are depicted in Table II. The measurements of TL, ATL, CW, HECO, and WECO were significantly larger on the right side among both sexes while the measurements of $\mathrm{CD}$ were significant larger on the left side for both sexes. The measurements of BD and $\angle \theta$ were also larger on the right side among both sexes, but the differences did not reach the level of statistical significance $(\mathrm{P}>0.05)$. For males, the measurements of TL1 and ATL1 were significant larger on the right side while the measurements of TL2 and ATL2 were significant larger on the left side. On the contrary, the measurements of TL1 and ATL1 for females were significant larger on the left side, while the measurements of TL2 and ATL2 were significant larger on the right side. In worthwhile adding that, the mean difference between sides in both sexes found to be less than $1 \mathrm{~mm}$. For males, the maximum bilateral asymmetry was the measurement of ATL1 (the mean leftright difference $=-0.587 \mathrm{~mm}$ ) followed by the measurement of TL1 (the mean left-right difference $=$ -

Table I. Descriptive statistics for conchal measurements in both sexes and sides among young Chinese adults (all measurements in mm with the exception of $\angle \theta$ in degree).

\begin{tabular}{|c|c|c|c|c|c|c|c|c|c|c|}
\hline \multirow{2}{*}{ Variable } & \multirow{2}{*}{$\begin{array}{l}\text { Males } \\
\text { Mean }\end{array}$} & \multicolumn{7}{|c|}{ Females } & \multicolumn{2}{|c|}{ Independent $t$-test } \\
\hline & & SD & Min & Max & Mean & SD & Min & Max & $t$-value & $p$-value* \\
\hline$T L(l e f t)$ & 17.55 & 1.21 & 14.75 & 20.60 & 16.64 & 1.21 & 13.93 & 19.73 & 6.562 & 0.000 \\
\hline$T L$ (right) & 17.85 & 0.90 & 16.69 & 21.75 & 17.03 & 1.22 & 14.54 & 20.33 & 5.837 & 0.000 \\
\hline TL1(left) & 10.44 & 1.09 & 7.37 & 12.93 & 9.89 & 1.20 & 6.90 & 12.81 & 4.189 & 0.000 \\
\hline TL1(right) & 10.98 & 0.97 & 8.56 & 12.95 & 9.74 & 1.00 & 7.40 & 12.32 & 5.074 & 0.000 \\
\hline TL2(left) & 9.11 & 1.07 & 6.37 & 11.82 & 8.26 & 1.15 & 5.74 & 11.35 & 5.808 & 0.000 \\
\hline TL2(right) & 8.78 & 0.89 & 6.20 & 11.55 & 8.49 & 1.08 & 6.01 & 11.49 & 6.943 & 0.005 \\
\hline ATL(left) & 16.43 & 1.41 & 12.79 & 19.71 & 15.35 & 1.06 & 12.60 & 18.31 & 7.222 & 0.000 \\
\hline$A T L$ (right) & 16.70 & 1.22 & 13.92 & 19.98 & 15.54 & 1.24 & 13.36 & 19.56 & 7.876 & 0.003 \\
\hline$A T L 1(l e f t)$ & 11.93 & 1.42 & 8.58 & 15.64 & 11.34 & 1.21 & 8.49 & 14.26 & 3.322 & 0.001 \\
\hline ATL1(right) & 12.52 & 1.42 & 9.08 & 15.27 & 11.20 & 1.17 & 9.19 & 13.89 & 3.775 & 0.001 \\
\hline ATL2(left) & 5.08 & 1.08 & 2.22 & 8.09 & 4.37 & 1.17 & 1.54 & 7.16 & 4.410 & 0.000 \\
\hline ATL2(right) & 4.78 & 1.09 & 3.28 & 7.78 & 4.65 & 1.04 & 2.87 & 7.72 & 5.353 & 0.000 \\
\hline$C W(l e f t)$ & 17.04 & 1.34 & 13.72 & 20.58 & 15.69 & 1.53 & 12.09 & 19.00 & 7.889 & 0.000 \\
\hline$C W$ (right) & 17.26 & 1.38 & 14.84 & 21.65 & 15.96 & 1.41 & 12.98 & 20.31 & 7.357 & 0.000 \\
\hline$B D(l e f t)$ & 8.53 & 1.53 & 5.55 & 14.12 & 7.85 & 1.50 & 5.27 & 12.33 & 3.326 & 0.001 \\
\hline$B D($ right $)$ & 8.92 & 1.99 & 5.92 & 14.87 & 7.98 & 1.55 & 4.98 & 11.83 & 3.565 & 0.001 \\
\hline$C D(l e f t)$ & 10.19 & 0.93 & 7.95 & 12.67 & 9.65 & 0.94 & 7.35 & 11.80 & 5.065 & 0.002 \\
\hline$C D$ (right) & 9.83 & 0.81 & 7.51 & 11.92 & 9.53 & 0.98 & 6.85 & 11.14 & 4.871 & 0.002 \\
\hline$H_{E_{C} O}(l e f t)$ & 9.82 & 1.06 & 5.13 & 12.12 & 9.46 & 0.91 & 6.84 & 12.62 & 3.132 & 0.002 \\
\hline$H_{E_{C} O}($ right $)$ & 9.93 & 1.13 & 5.98 & 12.98 & 9.71 & 0.62 & 6.97 & 12.80 & 3.778 & 0.002 \\
\hline$W_{E C O}(l e f t)$ & 7.74 & 1.10 & 4.35 & 10.75 & 7.14 & 0.86 & 4.27 & 9.29 & 5.336 & 0.000 \\
\hline$W_{E C O}($ right $)$ & 7.98 & 1.02 & 5.41 & 11.01 & 7.41 & 0.58 & 5.32 & 10.34 & 4.975 & 0.002 \\
\hline$<\theta($ left $)$ & 41.92 & 10.76 & 20.67 & 71.02 & 41.03 & 9.52 & 21.89 & 73.35 & 2.976 & 0.751 \\
\hline$<\theta$ (right) & 42.78 & 9.49 & 21.57 & 70.68 & 42.32 & 11.16 & 22.39 & 71.89 & 3.774 & 0.530 \\
\hline
\end{tabular}

$* \mathrm{P}$-value $<0.05$ is significant. 
ZHU, Z.; JI, X.; GAO, Z. \& HU, G. A morphometric study of auricular concha in the population of young Chinese adults. Int. J. Morphol., 35(4):1451-1458, 2017.

Table II. Bilateral differences of conchal measurements within the sexes using paired t-test (all measurements in $\mathrm{mm}$ with the exception of $\angle \theta$ in degree).

\begin{tabular}{lcccccccc}
\hline \multirow{2}{*}{ Variable } & \multicolumn{4}{c}{ Males (left-right) } & \multicolumn{4}{c}{ Females (left-right) } \\
& MD* & SEM* & $t$-value & $p$-value & MD & SEM & $t$-value & $p$ - \\
\hline$T L$ & -0.302 & 0.208 & -3.490 & 0.000 & -0.392 & 0.150 & -4.614 & 0.000 \\
$T L 1$ & -0.542 & 0.241 & -1.750 & 0.000 & 0.152 & 0.152 & 1.046 & 0.000 \\
$T L 2$ & 0.327 & 0.233 & 2.661 & 0.005 & -0.231 & 0.160 & -3.884 & 0.001 \\
$A T L$ & -0.270 & 0.250 & -4.279 & 0.035 & -0.187 & 0.215 & -1.820 & 0.018 \\
$A T L 1$ & -0.587 & 0.350 & -1.679 & 0.012 & 0.144 & 0.263 & 1.760 & 0.005 \\
$A T L 2$ & 0.303 & 0.278 & 1.282 & 0.018 & -0.283 & 0.248 & -1.325 & 0.003 \\
$C W$ & -0.221 & 0.253 & -3.634 & 0.034 & -0.268 & 0.213 & -2.495 & 0.017 \\
$B D$ & -0.389 & 0.305 & -1.409 & 0.177 & -0.133 & 0.260 & 0.361 & 0.321 \\
$C D$ & 0.362 & 0.177 & 0.306 & 0.000 & 0.121 & 0.153 & 0.267 & 0.000 \\
$H E_{C O}$ & -0.108 & 0.234 & -2.462 & 0.003 & -0.252 & 0.104 & -2.429 & 0.002 \\
$W_{E_{C O}}$ & -0.240 & 0.192 & -1.302 & 0.025 & -0.272 & 0.129 & -0.842 & 0.005 \\
$<\theta$ & -0.861 & 2.467 & -0.466 & 0.218 & -1.292 & 2.169 & -1.680 & 0.104 \\
\hline
\end{tabular}

*MD: mean difference; *SEM: std. error mean, *P-value $<0.05$ is significant.

$0.542 \mathrm{~mm})$. For females, the maximum bilateral asymmetry was the measurement of TL (the mean left-right difference $=-0.392 \mathrm{~mm}$ ) followed by the measurement of ATL2 (the mean left-right difference for females $=-0.283 \mathrm{~mm}$ ).

In addition, a unified coordinate system was established by MATLAB (MathWorks Inc., USA) to des- cribe the distribution of landmarks for all participants. The 3D coordinates of seven landmarks for each 3D digital model were extracted from the individual coordinate system. Therefore, the extracted coordinates of landmarks were transformed by considering $\mathrm{P} 3$ as $(0,0,0), \mathrm{P} 1$ as $(0$, P1-yi, 0), P5 as (P5-xi, P5-yi, 0), P2 as (P2-xi, P2-yi, P2zi), P4 as (P4-xi, P4-yi, P4-zi), P6 as (P6-xi, P6-yi, P6-zi) and $\mathrm{P} 7$ as (P7-xi, P7-yi, P7-zi) for each sample. Fig. 6 is an example depicts the distribution of seven left conchal landmarks for all 141 females. Furthermore, the basic shapes of auricular concha for both sexes and sides were established on the basis of the mean 3D coordinates of each landmark and the mean value of each measurement (Fig. 7).

\section{DISCUSSION}

There are population variations among people from different regions around the world in terms of auricle dimensions, which means it is not suitable to use foreign standards of auricle 20 dimensions as a guideline for Chinese. The auricular concha is an essential segment of auricle, but a comprehensive knowledge
Fig. 6. The distribution of seven landmarks on left auricular concha for all 141 females (From the front view). 


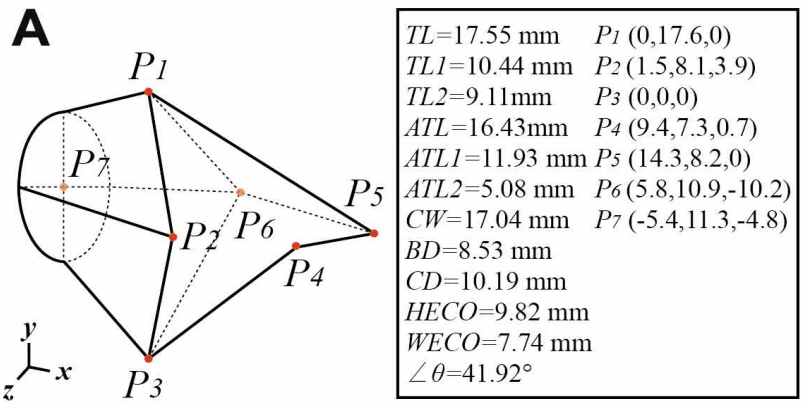

male left

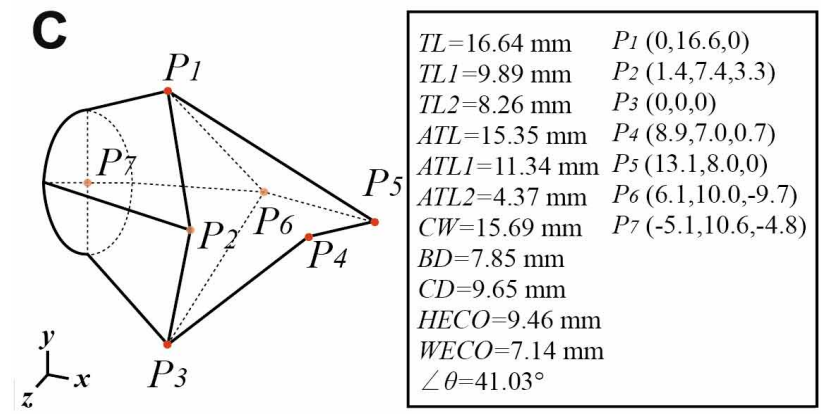

female left

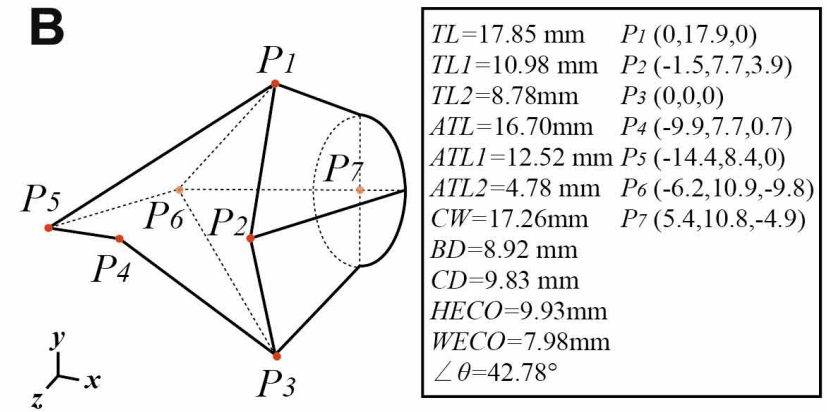

male right

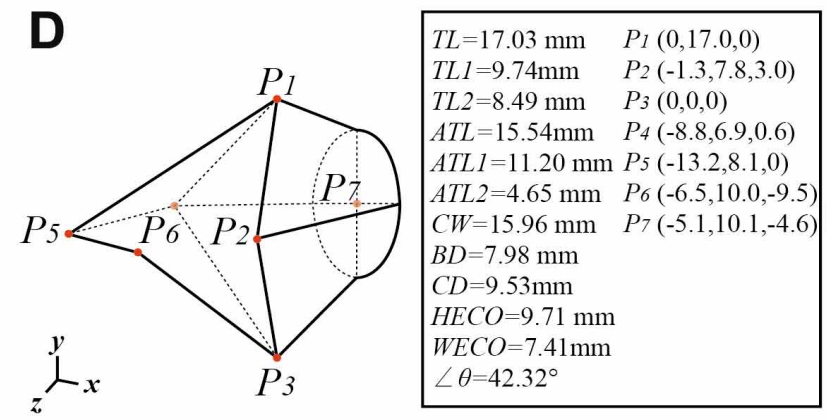

female right

Fig. 7. The basic shapes of auricular concha for both sexes and sides.

concerning morphometric dimensions of normal auricular concha is currently not available. Hence, this study provided a detailed knowledge about the morphometric measurements of normal auricular concha among young Chinese adults (Fig. 7). The results will be essential and beneficial for reconstruction and rectification of a deformed ear, and for the ergonomic design of hearing aid, earphone and earplug.

Previous studies have determined the sexual dimorphism and bilateral asymmetry of auricle using ear lengths and widths, lobule lengths and widths, and the conchal length and width. In a study by Ahmed \& Omer reported all measurements showed significantly sexual dimorphism except the lobular lengthsamong Sudanese Arabs. Sforza et al. noted ear length and width were significantly sexual dimorphism among Italians, while only ear length was sexual dimorphism among Americans from Rhode Island (Brucker et al.,). Murgod et al. noted the ear length and width on the right ears and ear length on left ear were sexual dimorphism. For bilateral asymmetry of auricle,

Farkas et al., (1992) reported asymmetry between left and right ears in children, but it tended to fade in adulthood. Barut \& Aktunc noted significantly larger left ears for all paprameters in children. On the contrary, the studies by Alexander $e t$ al. and Sforza $e t$ al. indicated good symmetry between left and right ears. In our study, twelve measurements were utilized to assess sexual dimorphism and bilateral asymmetry of auricular concha. The measurements in current study were different from the studies mentioned above. Therefore, the results of statistical analysis in our study cannot be compared with the study mentioned above.

To the best of our knowledge, a limited number of measurements in our study have been reported by previous studies, which were conchal width and depth, tragus length, and the height and width of ear canal opening.

Ahmed \& Omer reported there were significant sexual dimorphisms in conchal widths, and the mean widths of auricular concha were larger in males than females for both sides among Sudanese Arabs in the age range of 18-30 years. This result was coincident with our study. But, in current study the conchal width was significantly larger in the right side than left side for both sexes, which was contrast with Ahmed \& Omer (Table III). Additionally, the mean widths for both sexes and sides were all smaller in our study compared with Ahmed \& Omer and Purkait \& Singh. 
ZHU, Z.; JI, X.; GAO, Z. \& HU, G. A morphometric study of auricular concha in the population of young Chinese adults. Int. J. Morphol., 35(4):1451-1458, 2017.

Table III. Comparison of conchal measurements in various populations (measurements in $\mathrm{mm}$ ).

\begin{tabular}{|c|c|c|c|c|c|c|}
\hline Study & Measurements & Population & Left $(M)^{*}$ & Right (M)* & Left $(\mathrm{F})^{*}$ & Right (F)* \\
\hline Ahmed \& Omer (2015) & $C W$ & Sudanese Arabs & $18.95 \pm 1.87$ & $18.67 \pm 2.10$ & $17.96 \pm 1.71$ & $17.60 \pm 1.69$ \\
\hline Purkait \& Singh (2007) & $C W$ & Central Indians & $18.8 \pm 2.0$ & $18.7 \pm 2.0$ & & \\
\hline Wang et al. (2011) & $C W$ & North China & $17.9 \pm 2.1$ & $17.8 \pm 2.0$ & $18.0 \pm 2.2$ & $17.9 \pm 2.1$ \\
\hline Present study & $C W$ & Yong Chinese & $17.04 \pm 1.34$ & $17.26 \pm 1.38$ & $15.69 \pm 1.53$ & $15.96 \pm 1.41$ \\
\hline Purkait (2013) & $C D$ & Northwest Indians & & $15.7 \pm 0.8$ & & $15.7 \pm 0.8$ \\
\hline Present study & $C D$ & Yong Chinese & $10.19 \pm 0.93$ & $9.83 \pm 0.81$ & $9.65 \pm 0.94$ & $9.53 \pm 0.98$ \\
\hline Purkait (2013) & $T L$ & North west Indians & $16.5 \pm 0.9$ & $16.6 \pm 1.3$ & & \\
\hline Present study & $T L$ & Yong Chinese & $17.55 \pm 1.21$ & $17.85 \pm 0.90$ & $16.64 \pm 1.21$ & $17.03 \pm 1.22$ \\
\hline Yu et al. (2015) & $H_{E C O}$ & Taiwanese & 9.6 & 9.6 & 9.1 & 9.2 \\
\hline Present study & $H_{E C O}$ & Yong Chinese & $9.82 \pm 1.06$ & $9.93 \pm 1.13$ & $9.46 \pm 0.91$ & $9.71 \pm 7.14$ \\
\hline Yu et al. (2015) & $W_{E_{C O}}$ & Taiwanese & 6.8 & 6.7 & 6.3 & 6.3 \\
\hline Present study & $W_{E_{C} O}$ & Yong Chinese & $7.74 \pm 1.10$ & $7.98 \pm 1.02$ & $7.14 \pm 0.86$ & $7.41 \pm 0.58$ \\
\hline
\end{tabular}

*M: male; F: female

Meanwhile, they were also smaller than the population from north China (Wang et al.), especially for females (Table III). It revealed that the width of the auricular concha also varied in different geographic regions of China.

Table III indicated the mean depths of right auricular concha for both males and females in our study were much smaller than Purkait. The greater discrepancies may be attributed to without consistent standard for measuring the depth of auricular concha or may represent true differences between Chinese and Indians.

Purkait reported the mean length of right tragus was larger in males than females, which was consistent with current study. Additionally, it could be observed that the mean length of right tragus in young Chinese adults was larger than young India adults, regardless of males and females (Table III).

In a study by Yu et al. (2015) indicated that the average height and width of ear canal openings (ECO) for males were greater than those for females, irrespective of left or right side. This result was consistent with our investigation. Furthermore, from Table III, it can be observed that the average heights and widths of both right and left ECO in current study sample were little larger than the young adults from Taiwan, regardless of sex. Moreover, the mean height and width of ECO revealed that the crosssection of ECO was either an inverted pear or ellipse shape (Yu et al.). Hence, these finding should be considered in hearing aid manufacturing.

The measurements of TL1,TL2, ATL, ATL1, ATL2, $\mathrm{BD}$, and $\angle \theta$ in current study have not been assessed by previous study, but they are essential data for assessing the conchal morphometry. The basic shapes of auricular con- cha for both sexes and sides were established in this study, and they provided more intuitive data for clinical application and research.

The limitations of this study should not be neglected. The study sample was limited to the young Chinese adults in an age category of 18 - 28 years, but the ear is known to be affected by age. Therefore, the results of the current study may not be representative of the entire Chinese population. In the future studies, the population under the age of 18 years and above the age of 28 years should be measured and analyzed. Moreover, the age difference of the auricular concha should be assessed for Chinese population.

\section{CONCLUSIONS}

In conclusion, this study provides detailed information about the morphometric dimensions of normal auricular concha among young Chinese adults in an age group of 18- 28 years. The data generated in the present study could serve as a specific and useful database for the quantitative description of conchal morphometry in young Chinese adults. These intuitive data can be utilized in the diagnosis of congenital anomalies, ear constructive plastic surgeries, and particularly in ergonomic design of hearing aids.

\section{ACKNOWLEDGEMENTS}

The authors are grateful to all the participants who volunteered for this study. This study is supported by the National Natural Science Foundation of China (No.51305344). 
ZHU, Z.; JI, X.; GAO, Z. \& HU, G. A Estudio morfométrico de la concha auricular en una población de jóvenes adultos chinos. Int. J. Morphol. 35(4) :1451-1458, 2017.

RESUMEN: Actualmente no existen datos detallados de la concha auricular. Por lo tanto, el presente estudio tuvo como objetivo determinar doce medidas morfométricas de la concha auricular, investigar su dimorfismo sexual y asimetría bilateral, y establecer formas básicas de la concha para ambos sexos y lados. La muestra del estudio estaba compuesta por 310 jóvenes chinos de 18 a 28 años de edad. Se recolectaron y escanearon 141 impresiones de la oreja izquierda y 141 de la oreja derecha en mujeres; 169 impresiones de la oreja izquierda y 169 de la oreja derecha en hombres. Las coordenadas 3D de siete hitos en cada concha auricular se obtuvieron utilizando la tecnología de exploración 3D y la teoría de la curvatura. A partir de los hitos, se calcularon y analizaron doce medidas morfométricas de concha. La morfometría conchal indica la existencia significativa de dimorfismo sexual en esta muestra. En promedio, todas las mediciones fueron mayores en los hombres que en las mujeres, independientemente de los lados. Se observó una asimetría bilateral significativa entre las conchas izquierda y derecha en ambos sexos. Algunas medidas eran mayores en el lado derecho y otras medidas eran mayores en el lado izquierdo, pero la diferencia bilateral en ambas medidas fue menor a $1 \mathrm{~mm}$. Además, las formas básicas de concha para ambos sexos y lados se establecieron sobre la base de las coordenadas 3D medias de cada punto de referencia y el valor medio de cada medición. El método antropométrico de este estudio podría superar la dificultad de localizar los hitos de las estructuras del complejo auricular y lograr un mayor nivel de precisión en el procedimiento de medición. La descripción cuantitativa de la morfometría conchal será util para los cirujanos plásticos y para el diseño ergonómico de audífonos.

PALABRAS CLAVE: Impresión; Antropometría; Morfometría conchal; Dimorfismo sexual Asimetria bilateral.

\section{REFERENCES}

Ahmed, A. A. \& Omer, N. Estimation of sex from the anthropometric ear measurements of a Sudanese population. Leg. Med. (Tokyo), 17(5):3139, 2015.

Alexander, K. S.; Stott, D. J.; Sivakumar, B. \& Kang, N. A morphometric study of the human ear. J. Plast. Reconstr. Aesthet. Surg., 64(1):41-7, 2011.

Alvord, L. S. \& Farmer, B. L. Anatomy and orientation of the human external ear. J. Am. Acad. Audiol., 8(6):383-90, 1997.

Asai, Y.; Yoshimura, M.; Nago, N. \& Yamada, T. Why do old men have big ears? Correlation of ear length with age in Japan. B. M. J., 312(7030):582, 1996.

Barut, C. \& Aktunc, E. Anthropometric measurements of the external ear in a group of Turkish primary school students. Aesthetic Plast. Surg., 30(2):255-9, 2006

Bozkir, M. G.; Karakas , P.; Yavuz, M. \& Dere, F. Morphometry of the external ear in our adult population. Aesthetic Plast. Surg., 30(1):81-5, 2006.

Brucker, M. J.; Patel, J. \& Sullivan, P. K. A morphometric study of the external ear: age- and sex-related differences. Plast. Reconstr. Surg., 112(2):647$52,2003$.

Coward, T. J.; Scott, B. J.; Watson, R. M. \& Richards, R. Laser scanning of the ear identifying the shape and position in subjects with normal facial symmetry. Int. J. Oral. Maxillofac. Surg., 29(1):18-23, 2000.

Farkas, L. G.; Posnick, J. C. \& Hreczko, T. M. Anthropometric growth study of the ear. Cleft Palate Craniofac. J., 29(4):324-9, 1992.

Ferrario, V. F.; Sforza, C.; Ciusa, V.; Serrao, G. \& Tartaglia, G. M. Morphometry of the normal human ear: a cross-sectional study from adolescence to mid-adulthood. J. Craniofac. Genet. Dev. Biol., 19(4):22633, 1999.

Gualdi-Russo, E. Longitudinal study of anthropometric changes with ageing in an urban Italian population. Homo, 49(3):241-59, 1998

Jung, H. S. \& Jung, H. S. Surveying the dimensions and characteristics of Korean ears for the ergonomic design of ear-related products. Int. J. Ind. Ergon., 31(6):361-73, 2003.

Kang, H. J.; Hu, K. S.; Song, W. C.; Kwon, H. J.; Park, D. K.; Sohn, H. J.; Koh, K. S.; Han, S. H.; Paik, D. J.; Chung, R. H. \& Kim, H. J. Physical anthropologic characteristics of the auricle through the metric and nonmetric analysis in Korean young adults. Korean J. Phys. Anthropol., 19(4):255-65, 2006.

Liu, B. S. Incorporating anthropometry into design of ear-related products. App. Ergon., 39(1):115-21, 2008.

Liu, B. S.; Tseng, H. Y. \& Chia, T. C. Reliability of external ear measurement obtained by direct, photocopier scanning and photo anthropometry. Ind. Eng. Manag. Syst., 9(1):20-7, 2010.

Murgod, V.; Angadi, P.; Hallikerimath, S. \& Kale, A. Anthropometric study of the external ear and its applicability in sex identification: assessed in an Indian sample. Aust. J. Forensic Sci., 45(4):431-44, 2013.

Niemitz, C.; Nibbrig, M. \& Zacher, V. Human ears grow throughout the entire lifetime according to complicated and sexually dimorphic patterns-conclusions from a cross-sectional analysis. Anthropol. Anz., 65(4):391413, 2007

Purkait, R. \& Singh, P. Anthropometry of the normal human auricle: a study of adult Indian men. Aesthetic Plast. Surg., 31(4):372-9, 2007.

Purkait, R. Progression of growth in the external ear from birth to maturity: a 2-year follow-up study in India. Aesthetic Plast. Surg., 37(3):605-16, 2013.

Sforza, C.; Grandi, G.; Binelli, M.; Tommasi, D. G.; Rosati, R. \& Ferrario, V. F. Age- and sex-related changes in the normal human ear. Forensic Sci. Int., 187(1-3):110.e1-7, 2009.

Sharma, A.; Sidhu, N. K.; Sharma, M. K.; Kapoor, K. \& Singh, B. Morphometric study of ear lobule in northwest Indian male subjects. Anat. Sci. Int., 82(2):98-104, 2007.

Tatlisumak, E.; Yavuz, M. S.; Kutlu, N.; Asirdizer, M.; Yoleri, L. \& Aslan, A. Asymmetry, handedness and auricle morphometry. Int. J. Morphol., 33(4):1542-8, 2015.

Wang, B.; Dong, Y.; Zhao, Y.; Bai, S. \& Wu, G. Computed tomography measurement of the auricle in Han population of north China. J. Plast. Reconstr. Aesthet. Surg., 64(1):34-40, 2011.

Yu, J. F.; Lee, K. C.; Wang, R. H.; Chen, Y. S.; Fan, C. C.; Peng, Y. C.; Tu, T. H.; Chen, C. I. \& Lin, K. Y. Anthropometry of external auditory canal by non-contactable measurement. Appl. Ergon., 50:50-5, 2015.

\section{Corresponding author}

Xiaomin Ji

School of Mechanical and Precision Instrument Engineering, Xi'an University of Technology

No. 5 Jinhua Road, Xi'an 710048

CHINA

E-mail: shejizhu@hotmail.com

Received: 27-06-2017

Accepted: 11-08-2017 